\title{
ACHROMATIC NUMBERS FOR CIRCULANT GRAPHS AND DIGRAPHS
}

\author{
Gabriela Araujo-Pardo \\ Juan José Montellano-Ballesteros \\ Instituto de Matemáticas \\ Universidad Nacional Autónoma de México, México \\ e-mail: garaujo@matem.unam.mx \\ juancho@matem.unam.mx \\ Mika OLSEN \\ Departamento de Matemáticas Aplicadas y Sistemas \\ UAM-Cuajimalpa, México \\ e-mail: olsen@correo.cua.uam.mx
}

AND

Christian Rubio-Montiel

División de Matemáticas e Ingeniería, FES Acatlán

Universidad Nacional Autónoma de México, Naucalpan, Mexico

e-mail: christian.rubio@acatlan.unam.mx

\begin{abstract}
In this paper, we determine the achromatic and diachromatic numbers of some circulant graphs and digraphs each one with two lengths and give bounds for other circulant graphs and digraphs with two lengths. In particular, for the achromatic number we state that $\alpha\left(C_{16 q^{2}+20 q+7}(1,2)\right)=8 q+5$, and for the diachromatic number we state that $\operatorname{dac}\left(\vec{C}_{32 q^{2}+24 q+5}(1,2)\right)=$ $8 q+3$. In general, we give the lower bounds $\alpha\left(C_{4 q^{2}+a q+1}(1, a)\right) \geq 4 q+1$ and $\operatorname{dac}\left(\vec{C}_{8 q^{2}+2(a+4) q+a+3}(1, a)\right) \geq 4 q+3$ when $a$ is a non quadratic residue of $\mathbb{Z}_{4 q+1}$ for graphs and $\mathbb{Z}_{4 q+3}$ for digraphs, and the equality is attained, in both cases, for $a=3$.

Finally, we determine the achromatic index for circulant graphs of $q^{2}+$ $q+1$ vertices when the projective cyclic plane of odd order $q$ exists.

Keywords: circulant graphs, complete colorings, achromatic number, achromatic index.
\end{abstract}

2010 Mathematics Subject Classification: 05C15. 


\section{REFERENCES}

[1] G. Araujo-Pardo, J.J. Montellano-Ballesteros, M. Olsen and C. Rubio-Montiel, The diachromatic number of digraphs, Electron. J. Combin. 25 (2018) \#P3.51 doi: $10.37236 / 7807$

[2] G. Araujo-Pardo, J.J. Montellano-Ballesteros, C. Rubio-Montiel and R. Strausz, On the pseudoachromatic index of the complete graph III, Graphs Combin. 34 (2018) $277-287$. doi:10.1007/s00373-017-1872-6

[3] G. Araujo-Pardo, J. J. Montellano-Ballesteros and R. Strausz, On the pseudoachromatic index of the complete graph, J. Graph Theory 66 (2011) 89-97. doi:10.1002/jgt.20491

[4] G. Araujo-Pardo, J.J. Montellano-Ballesteros, R. Strausz and C. Rubio-Montiel, On the pseudoachromatic index of the complete graph II, Bol. Soc. Mat. Mex. 20 (2014) $17-28$. doi:10.1007/s40590-014-0007-9

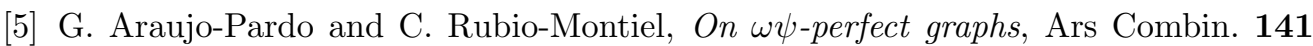
(2018) 375-387.

[6] F. Bories and J. Jolivet, On complete colorings of graphs, in: Recent Advances in Graph Theory, Proc. Second Czechoslovak Sympos., Prague, 1974, (Academia, Prague, 1975) 75-87.

[7] A. Bouchet, Indice achromatique des graphes multiparti complets et réguliers, Cahiers Centre Études Rech. Opér. 20 (1978) 331-340.

[8] D.M. Burton, Elementary Number Theory, Second Edition (W.C. Brown Publishers, Dubuque, IA, 1989).

[9] N. Cairnie and K. Edwards, Some results on the achromatic number, J. Graph Theory 26 (1997) 129-136. doi:10.1002/(SICI)1097-0118(199711)26:3〈129::AID-JGT3〉3.0.CO;2-T

[10] G. Chartrand and P. Zhang, Chromatic Graph Theory (Chapman and Hall/CRC Press, New York, 2008). doi:10.1201/9781584888017

[11] M. Dębski, Z. Lonc and P. Rzążewski, Achromatic and harmonious colorings of circulant graphs, J. Graph Theory 87 (2018) 18-34. doi:10.1002/jgt.22137

[12] K.J. Edwards, Harmonious chromatic number of directed graphs, Discrete Appl. Math. 161 (2013) 369-376. doi:10.1016/j.dam.2012.09.003

[13] F. Harary, S. Hedetniemi and G. Prins, An interpolation theorem for graphical homomorphisms, Port. Math. 26 (1967) 453-462.

[14] P. Hell and D.J. Miller, Graph with given achromatic number, Discrete Math. 16 (1976) 195-207. doi:10.1016/0012-365X(76)90099-6 
[15] M. Horňák, Achromatic index of $K_{12}$, Ars Combin. 45 (1997) 271-275.

[16] M. Horňák, Š. Pčola and M. Woźniak, On the achromatic index of $K_{q^{2}+q}$ for a prime q, Graphs Combin. 20 (2004) 191-203. doi:10.1007/s00373-004-0550-7

[17] R.E. Jamison, On the edge achromatic numbers of complete graphs, Discrete Math. 74 (1989) 99-115. doi:10.1016/0012-365X(89)90202-1

[18] R.E. Jamison, On the achromatic index of $K_{12}$, in: Proceedings of the Twentysecond Southeastern Conference on Combinatorics, Graph Theory and Computing, Baton Rouge, 1991, Congr. Numer. 81 (1991) 143-148.

[19] F. Kárteszi, Introduction to Finite Geometries (North-Holland Publ. Co., New York, 1976).

[20] V. Neumann-Lara, The dichromatic number of a digraph, J. Combin. Theory Ser. B 33 (1982) 265-270. doi:10.1016/0095-8956(82)90046-6

[21] É. Sopena, Complete oriented colourings and the oriented achromatic number, Discrete Appl. Math. 173 (2014) 102-112. doi:10.1016/j.dam.2014.03.015

[22] C. M. Turner, R. Rowley, R. Jamison and R. Laskar, The edge achromatic number of small complete graphs, Congr. Numer. 62 (1988) 21-36.

[23] V. Yegnanarayanan, The pseudoachromatic number of a graph, Southeast Asian Bull. Math. 24 (2000) 129-136. doi:10.1007/s10012-000-0129-z

[24] V. Yegnanarayanan, Graph colourings and partitions, Theoret. Comput. Sci. 263 (2001) 59-74.

doi:10.1016/S0304-3975(00)00231-0

Received 18 November 2019

Revised 20 April 2020

Accepted 20 April 2020 